\title{
PRESBYOPIA AMONG PUBLIC SENIOR HIGH SCHOOL TEACHERS IN THE KUMASI METROPOLIS
}

\author{
D. B. KUMAH ${ }^{1}$, S. Y. LARTEY ${ }^{2}$ and K. AMOAH-DUAH ${ }^{1}$ \\ ${ }^{1}$ Kwame Nkrumah University of Science and Technology, Private Mail Bag, Kumasi, Ghana ${ }^{2}$ Kwame \\ Nkrumah University of Science and Technology, Department of Eye, Ear, Nose and Throat, Kumasi, Ghana \\ ${ }^{2}$ Eye Clinic, Komfo Anokye Teaching Hospital, P O Box 1934, Kumasi, Ghana
}

Corresponding Author: Dr. Seth Y. Lartey

Conflict of Interest: None Declared

\section{SUMMARY}

Background: Presbyopia if uncorrected causes inability to see and do near work. It is unavoidable as one ages. High school teachers whose work depends much on near work need proper and adequate correction of their presbyopia to increase effectiveness and efficiency.

Objectives: The aim was to determine the uptake of correction and prescription for presbyopia of presbyopic teachers of public Senior High School (S.H.S.). Design: Descriptive cross-sectional study.

Methods: The study was conducted in 12 public S.H.S. in the Kumasi, with a total sample size of 298. Questionnaire was administered to teachers. Their visual acuity, refraction and ophthalmoscopy were done.

Results: The prevalence of presbyopia among the teachers was $68.1 \%$. Out of the number examined $197(66.1 \%)$ were males and 10(33.9\%) were females. Amongst the presbyopes 60 did not have presbyopic correction, representing $29.6 \%$ of the presbyopes. A total of 52 presbyopic teachers required an add of +2.00DS and this was the highest diopter of correction needed $(25.6 \%)$. Among those with presbyopic correction $55.5 \%$ of them use single vision type of correction whiles the remaining $44.5 \%$ use bifocals. Out of the $48 \%$ presbyopic teachers who have had their presbyopia corrected before, $6 \%$ were not wearing their correction.

Conclusion: The study has demonstrated a relatively higher prevalence of uncorrected presbyopia amongst teachers in public Senior High Schools in the Kumasi Metropolis of 29.6\%. Among those with correction 6 $\%$ were not using their correction. Proper and adequate correction is needed by presbyopic teachers through screening to ensure their maximum performance.

Keywords: Presbyopia, teachers, lens correction, prescription, senior high school.
Email:sylartey@yahoo.com, seth.Lartey@yahoo.co.uk

\section{INTRODUCTION}

Presbyopia is an age-related loss of accommodation that results in an inability to focus at near distances. ${ }^{1,2}$ It is the most common physiological change occurring in the adult eye and is thought to cause universal near vision impairment with advancing age. ${ }^{3,4}$

It is generally first reported clinically between 40 and 45 years of age, with its peak onset between ages 42 and 44 years, and generally occurs in females earlier before 40 years. ${ }^{5}$ It progresses gradually over a number of years. From approximately age 52 years on, the prevalence of presbyopia is considered to be essentially $100 \%$; however, its prevalence across all ages in the population is $31 \% .^{6}$

The main symptoms include vision at the customary near-working distance being blurred or can be sustained only with excessive effort and some eye discomfort and also reading material must be held farther away to be seen more clearly. ${ }^{6}$ Presbyopia cannot be cured, but individuals can compensate for it by wearing reading (single-vision), bifocal, or progressive eyeglasses. A convex lens is used to make up for the lost automatic focusing power of the eye. ${ }^{7}$

Presbyopia is not simply an inconvenience; it has significant effects on quality of life, particularly in the lives of teachers, whose work depends mostly on reading and writing. In Ghana where most of the marking of examination scripts and evaluation of students work in class are done manually, a teacher might not perform efficiently if he/she is unable to read and mark correctly. So corrective spectacle for presbyopia are necessary.

But the type of correction used depends much on the individual's preference and normally the environment in which he finds himself. Teachers who do a lot of close work may consider single-vision reading glasses. Others who work between far and near distance intermittently or have distant vision problems may consider multifocals (bifocal or progressive). 
Though the choice of corrective lens depends on the client, a wrong choice can affect his comfort and sometimes ocular health (in relation to contact lens), and this can lead to the client not putting on his correction although he might have had the right power of correction.

Full correction is needed by teachers for maximum performance. Yet there is no data in Kumasi to indicate if they are getting their right correction. Results of the study will help inform policy makers give maximum help on teachers' correction. The aim was to determine the uptake of correction and prescription for presbyopia of presbyopic teachers of public Senior High School (S.H.S.).

The specific objectives included determining the number of presbyopic teachers (both corrected and uncorrected), the type of presbyopic prescription used and the number of presbyopic teachers with corrected presbyopia who are not wearing their prescription.

\section{METHODS}

\section{Sampling Technique}

All public Senior High Schools in the Kumasi Metropolis were listed as eligible for the study. The teachers were divided into clusters according to their school.. Teachers were randomly selected from each cluster using simple random technique.

A sample size of 338 was calculated and 298 teachers were screened, giving us a respondent rate of 88.2\%.Materials employed in the collection of the data included Snellen distance and near acuity charts, trial case and accessories, trial frame and a Heine ophthalmoscope.

\section{Data Collection}

Visual acuity was tested separately for distant and near vision using Snellen charts. Teachers with visual acuity (VA) less than 6/9 were refracted for both distance and near with the help of a trial frame, a trial case and some of its accessories.

Teachers with VA of $6 / 9$ or better were subjected to near refraction. Myopes with a visual acuity of $6 / 12$ or worse were also made to wear their correction before taking the near visual acuity test. For the purpose of this study people who could not read N6 and emmetropes who are 40 years and above were considered as presbyopes.

A questionnaire was also used to determine personal information such as name, age, sex and the type of correction used to correct their near vision, whether their presbyopia has been corrected before and how often they wear their correction.

\section{Data Analysis}

The SPSS 16 software was employed in entering the data,analyzing them and drawing the tables. Percentages and prevalence were calculated for all the variables

\section{RESULTS}

More males were screened than females (197/298, $66.1 \%$ ). Of the teachers, $71.1 \%$ were between the ages of 36-55 with 46-50 having the highest frequency 60(20.1\%). There were 203 teachers with presbyopia and the prevalence of presbyopia was $68.1 \%$. Amongst the presbyopes, $29.6 \%$ (60) did not have presbyopic correction.

The most common correction required was +2.00DS representing $25.6 \%$ (52) of presbyopic teachers. Also presbyopic teachers requiring this correction (+2.00DS) represented the largest group who have had previous correction before. All the presbyopic teachers who were having an add of +2.50DS had their presbyopia corrected before.

Among those who had presbyopic correction, (55.5\%) used single vision type of prescription while the remaining $(44.5 \%)$ used bifocals. A total of $46 \%$ of the teachers who were presbyopic had distant correction. And amongst these (the 46\%), 90.5\% preferred bifocal to single vision prescription.

Among those who do not wear distant correction, $94.6 \%$ preferred to use single vision. Table 1 . A total of $143(48 \%)$ of presbyobic teachers have had previous prescriptions for correction. However of the presbyobic teachers who have had previous prescription for correction, 6\% were non compliant and not wearing their spectacles.

Table 1 Types of near presbyopic prescription

\begin{tabular}{|c|l|l|l|}
\hline & \multicolumn{3}{|l|}{ Type of near prescription used } \\
\hline $\begin{array}{l}\text { Have distant } \\
\text { correction }\end{array}$ & $\begin{array}{l}\text { Single } \\
\text { vision }\end{array}$ & Bifocal & Total \\
\hline Yes & $6(9.5 \%)$ & $57(90.5 \%)$ & $63(100.0 \%)$ \\
\hline No & $70(94.6 \%)$ & $4(5.4 \%)$ & $74(100.0 \%)$ \\
\hline Total & $76(55.5 \%)$ & $61(44.5 \%)$ & $137(100.0 \%)$ \\
\hline
\end{tabular}

\section{DISCUSSION}

Prevalence of presbyopia in this study was $68.1 \%$. This seems to be high as compared to the prevalence studies in Brazil, 55\%, ${ }^{8}$ Southern India, $55 \%^{5}$ and in Ghanaian women, $65 \%$. 
A total of $30 \%$ of the presbyopic teachers had no correction. Holden et al estimated 517 million people out of 1.04 billion presbyopes $(49.7 \%)$ to be without correction or having inadequate correction. ${ }^{10}$ This is higher than what we found among teachers. This may be because teachers are educated and are expected to have been more receptive to uptake of correction for their error.

The 49.7\% in Holden's study was estimated and therefore cannot be said to represent the actual population. They also used the general population whilst we restricted the population to high school teachers. Of these $29.6 \%$ had high presbyopia which could affect their performance. Perhaps some teachers may be reluctant to give class exercise and assignment in order to avoid marking.

Amongst presbyopes who have had previous correction +2.00DS was the most common correction required $52(25.6 \%)$. And this could be as a result of increasing difficulty in performing near work from this stage (+2.00DS to +2.50DS) without correction. Even though it was expected for presbyopic teachers who required +0.75 to $+1.00 \mathrm{DS}$ correction to have the lowest presbyopic correction +1.50DS was the lowest prevalence of presbyopic correction.

A survey of ocular morbidity in rural Uganda found patients with uncorrected presbyopia accounting for $48 \%$ of those presenting with visual impairment. ${ }^{11} \mathrm{~A}$ total of $55.5 \%$ preferred single vision prescription to bifocal, probably to avoid the inconvenience of having to put on their correction most of the time.

Among those who wear distant correction the bifocal was the preferred choice since opting for a single vision correction meant having to change spectacles during teaching. The teacher has to use his/her presbyopic correction to read and his distant correction to look at his/her pupils during teaching. None of them wore progressive lens and this could be that progressive lenses are relatively expensive and unknown to most clients.

Although $48 \%$ of the presbyopic teachers have been corrected before $6 \%$ were not wearing their prescription. There could be many reasons for that including damaged or lost spectacle and discomfort or poor vision when wearing the spectacles. Further studies will be required to determine the reasons for non-compliance. A survey of refractive error and presbyopia in adults aged 40 years and above in TimorLeste found $4.0 \%$ (56/1414) who were non compliant and not wearing their correction.
In that study the factors responsible for non compliance were: Perceived inability to afford spectacles $(16.1 \%$; 9/56), poor cosmetics $(41.1 \%$; 23/56) and embarrassment $(37.5 \% ; 21 / 56)$, with neither being gender biased. Unwillingness to wear spectacles was associated with illiteracy, but not with gender or rural living. ${ }^{12}$

There seems to be hardly any published papers on presbyopia among high school teachers in the African setting and it is difficult to compare our work to others in the region. The limitation of this study was that some of the selected teachers could not participate due to their work schedule. Four principals did not consent to data collection in their school the results cannot be extrapolated for the Ghana.

\section{CONCLUSION}

The study has demonstrated a high prevalence of uncorrected presbyopia amongst teachers in public Senior High Schools in the Kumasi Metropolis of 30\%. It has also shown that among those with correction $6 \%$ were non compliant and not using their correction. Considering that proper and adequate correction is needed by presbyopic teachers to ensure maximum performance, all S.H.S. teachers 35 years and above should be encouraged to go for presbyopic screening and wear their spectacles. This will help improve performances in the teaching profession. Teachers who have their presbyopia corrected should seek professional advice on the type of prescription suitable for them. Further studies are required to find out why some teachers who have their presbyopia corrected do not put on their prescription and to determine the relationship between correction of presbyopia and performance of S.H.S. teachers and their students.

\section{ACKNOWLEDGMENT}

We thank the Ghana Education Service and the various head teachers for their support. We also want to show our appreciation to Oswald Kofi Domfeh who did most of the data entry and typing without whose help this paper wouldn't have been completed.

\section{REFERENCES}

1. Patel, I. and West, S.K. Presbyopia: prevalence, impact, and interventions. Community Eye Health 2007;20(63): 40-41.

2. Glasser. A and Campbell C.W.M. Presbyopia and the optical changes in the human crystalline lens with age. Vision Research 1998;38(2):209-229.

3. Glasser, A and Campbell C.W.M. Biometric, optical and physical changes in the isolated human crystalline lens with age in relation to presbyopia. Vision Research 1999;39(11):1991-2015. 
4. Koretz, J.F., Kaufman, P.L., Neider, M.W. and Goeckner, P.A. Accommodation and presbyopia in the human eye-aging of the anterior segment. Vision Research 1989;29(12):1685-1692.

5. Nirmalan, P.K., Krishnaiah, S., Shamanna, B.R., Rao, G.N., Thomas, R. A population-based assessment of presbyopia in the state of Andhra Pradesh, South India: the Andhra Pradesh Eye Disease Study Invest Ophthalmol Vis Sci 2006; 47: 2324-2328.

6. William, J.B. (). Borish's Clinical Refraction. $2^{\text {nd }}$ Edition, Butterworth-Heinemann. 2006. 131-132.

7. Longe, J.L.. The Gale Encyclopedia of Medicine. $2^{\text {nd }}$ Edition, Gale Group, 2002. 4: 2713-2714.

8. Duarte, W.R., Barros, A.J., Dias-da-Costa, J.S., Cattan, J.M. Prevalence of near vision deficiency and related factors: a population-based study. Cad Saude Publica 2003;19: 551-559.
9. Morny, F.K. Correlation between presbyopia, age and number of births of mothers in the Kumasi area of Ghana. Ophthalmic Physiol Opt 1995;15: 463-466.

10. Holden, B.A., Fricke, T.R., Ho, S.A., Schlenther, G., Cronjé, S., Burnett, A., Papas, E., Naidoo, K.S., Frick, K.D. Global vision impairment due to uncorrected presbyopia Arch Ophthalmol 2008;126(12):1731-1739.

11. Kamali, A., Whitworth, J.A., Ruberantwari, A., Mulwanyi, F., Acakara, M., Dolin, P. Causes and prevalence of non-vision impairing ocular conditions among a rural adult population in SW Uganda. Ophthalmic Epidemiol 1999;6: 41-48.

12. Ramke, J., Toit, R., Palagyi1, A., Brian, G., Naduvilath T. Correction of refractive error and presbyopia in Timor-Leste. $\mathrm{Br} J$ Ophthalmol 2007;91:860-866. 